\title{
Os vários telejornalismos brasileiros
}

DOI: https://doi.org/10.1590/1809-58442020111

\author{
Gustavo Teixeira de Faria Pereira ${ }^{1}$ \\ https://orcid.org/0000-0002-5185-284X
}

\begin{abstract}
${ }^{1}$ (Universidade Federal de Juiz de Fora, Faculdade de Comunicação Social, Programa de Pós-Graduação em Comunicação. Juiz de Fora - MG, Brasil).
\end{abstract}

EMERIM, C.; COUTINHO, I.; FINGER, C. (Orgs.). Epistemologias do telejornalismo brasileiro. Florianópolis: Editora Insular, 2018.

O livro "Epistemologias do telejornalismo brasileiro" (EMERIM; COUTINHO; FINGER, 2018), sétimo volume da coleção Jornalismo Audiovisual, idealizada pelos integrantes da Rede de Pesquisadores em Telejornalismo (Telejor), em parceria com a Editora Insular, tem como objetivo apresentar os resultados de pesquisa, métodos e conceitos-chave sobre telejornalismo e audiovisual desenvolvidos pelo grupo. Além disso, busca difundir o conhecimento de seus vários integrantes, observando as particularidades das instituições a que os pesquisadores são vinculados e a diversidade regional que compõe a Rede Telejor.

Com uma proposta de intensificação teórico-reflexiva, a proposta da obra é a de contribuir e fortalecer os estudos

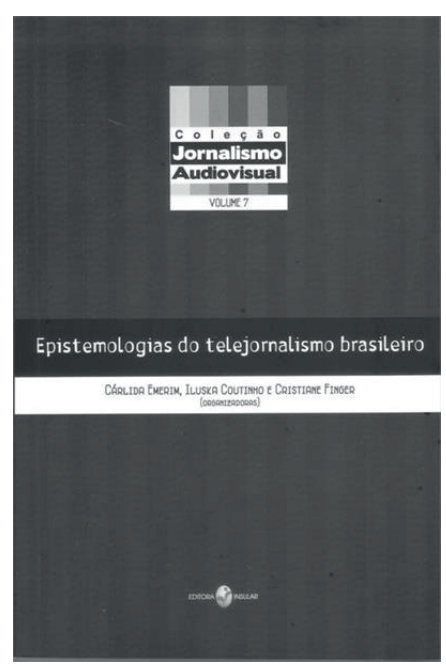
do campo do Telejornalismo em seus diferentes âmbitos de produção de conhecimento. Para isso, 33 professores e pesquisadores participaram como autores do livro, organizado por Cárlida Emerim, Iluska Coutinho e Cristiane Finger.

O grupo atua ativamente em encontros acadêmicos da SBPJOR, Compós e Intercom na divulgação de suas pesquisas desenvolvidas, no debate acerca do telejornalismo e audiovisual no âmbito da graduação e na produção de conhecimento científico para programas de pósgraduação e toda a comunidade acadêmica. Anteriormente, foram publicadas as obras: " $O$ Brasil (é)ditado" (COUTINHO; PORCELLO; VIZEU, 2012), "\#telejornalismo: nas ruas e nas telas" (PORCELLO; VIZEU; COUTINHO, 2013), "Telejornalismo em questão" (PORCELLO; VIZEU; COUTINHO; MELLO, 2014), "Telejornalismo e Praça Pública" (VIZEU; MELLO; PORCELLO; COUTINHO, 2015), "Telejornalismo e Poder” (EMERIM; FINGER; PORCELLO, 2016), e "Desafios do telejornalismo- ensino, pesquisa e extensão" (EMERIM; COSTA; PORCELLO, 2017). 
A obra mais recente, aqui apresentada, se divide em três seções que buscam lançar um olhar mais atento para o campo do telejornalismo e do jornalismo audiovisual.

Na primeira seção, composta por sete capítulos, observa-se a preocupação na definição do telejornalismo como um campo social e de pesquisa, destacando o papel da televisão como central na cultura brasileira. E já no primeiro capítulo, Edna de Mello Silva apresenta as seis fases do telejornalismo no Brasil, que vai desde a chegada da TV, nos anos 1950, até os dias atuais, sendo: 1) Telejornalismo Falado; 2) Telejornalismo Reportado; 3) Telejornalismo All News; 4) Telejornalismo Convergente; 5) Telejornalismo Expandido; e 6) Telejornalismo Imersivo.

Os capítulos 2 e 3 trabalham com uma intersecção entre telejornalismo e educação. No segundo, Laerte Cerqueira e Alfredo Vizeu trabalham os saberes da Pedagogia da Autonomia e a filosofia de Paulo Freire. Já no capítulo 3, Elizena Rossy e Dione Moura tomam o Telejornalismo como espaço de criação de laços sociais e controle social.

Nos capítulos de 4 a 7 são apresentadas diferentes angulações que buscam compreender como tem se dado a produção acadêmica, bem como os estudos sobre Telejornalismo nos Programas de Pós-Graduação de diferentes instituições de ensino das regiões Sul, Sudeste e Nordeste, representadas por Cárlida Emerim, Cristiane Finger e Flávio Porcello no Sul; Christina Ferraz Musse, Claudia Albuquerque Thomé, Marco Aurélio Reis e Beatriz Becker no Sudeste; e Vitor Belém, Lívia Cirne e Paulo Lins Cajazeira no Nordeste.

A segunda seção, intitulada “Olhares e escutas: Métodos para experimentar o telejornalismo” traz mais sete capítulos em que os autores apresentam diversas propostas metodológicas para se estudar o telejornalismo e sua complexidade.

Iluska Coutinho inicia a seção propondo como nova metodologia a Análise da Materialidade Audiovisual, que tem como objetivo a investigação das narrativas jornalísticas audiovisuais como uma unidade, observando suas particularidades.

Outras propostas colocadas como possíveis para o estudo do telejornalismo são as Análises de Conteúdo e de Discurso, principalmente para a Leitura Crítica da Mídia, por Ana Carolina Temer; uma abordagem hermenêutica das narrativas de identidade na TV, por Célia Mota; Análise Holística do Audiovisual, com ênfase na parte descritiva e no olhar para o gênero; e propostas de um telejornalismo mais plural e igual, tal como aborda Ariane Pereira.

Ainda na segunda seção, Flora Neves, no capítulo 13, trabalha com a questão dos apresentadores como mitos e tradutores de realidade no telejornalismo, enquanto no 14, Lara Linhalis Guimarães e Evandro Medeiros trabalham com a associação entre jornalista e a figura dos xamãs em tribos ameríndias no papel de tradução da realidade.

Na terceira e última seção do livro, "Práticas, o saber do jornalismo audiovisual”, os autores buscam trazer experiências telejornalísticas e audiovisuais que justificam a grande importância dos estudos de telejornalismo no Brasil.

Já no primeiro texto da seção, Letícia Renault traz o exemplo de Sandra Passarinho que estreou na televisão em 1969 e se tornou a primeira repórter brasileira a atuar como correspondente internacional ao cobrir a Revolução dos Cravos em Portugal (1974), a partir 
da valorização do trabalho da mulher do telejornalismo e na busca por um amadurecimento da sociedade brasileira.

Na sequência, é trabalhada a questão da extensão universitária como prática laboratorial da produção de reportagem e entrevista ao vivo na Internet, bem como os modos de endereçamento e as narrativas do real a partir da busca por aproximação e maior vinculação com o público no programa Bom Dia Brasil, em texto escrito por Fabiana Piccinin, Maura Martins e Michele Negrini.

A obra segue com exemplos de busca por inclusão de culturas invisibilizadas no Brasil com Adriana Nilo, que trabalha com a representação dos povos indígenas, e com Vanessa Paiva, que apresenta o projeto Poéticas dos Encontros, desenvolvido por estudantes da Faculdade de Comunicação da UFSJ-MG.

Na última parte da terceira seção, Jhonatan Mata apresenta “o amador” e as estratégias amadoras que têm conquistado cada vez mais espaço nas narrativas dos telejornais. Já Beatriz Cavenaghi traça um caminho dos apresentadores no telejornalismo brasileiro, que vai da busca por neutralidade até a presença do jornalista como estratégia de legitimação e credibilidade.

Por fim, Carlos Tourinho trabalha com as potencialidades do novo telejornalismo, a partir da experiência da TV Digital Terrestre (TDT), que veio para substituir a televisão analógica.

A obra busca mapear as novas formas de se fazer audiovisual, bem como produzir um diálogo entre professores e estudantes de telejornalismo, reforçando que há diversas maneiras de se estudar e pesquisar os “telejornalismos” e o audiovisual.

\section{Referências}

COUTINHO, I. M. S.; PORCELLO, F.; VIZEU, A. (Orgs.). O Brasil (é)ditado. 1. ed. Florianópolis: Insular, 2012. v. 1. 312 p.

EMERIM, C.; COSTA, C. F.; PORCELLO, F. C. (Orgs.). Desafios do Telejornalismo: ensino, pesquisa e extensão. 1. ed. Florianópolis: Insular, 2017. v. 6. 214 p.

EMERIM, C.; FINGER, C.; PORCELLO, F. C. (Orgs.). Telejornalismo e Poder. 1. ed. Florianópolis: Insular, 2016. v. 5. 340 p.

PORCELLO, F.; VIZEU, A.; COUTINHO, I. M. S. (Orgs.). \#telejornalismo: nas ruas e nas telas. 1. ed. Florianópolis: Insular, 2013. v. 1. 240 p.

PORCELLO, F.; VIZEU, A.; COUTINHO, I. M. S.; MELLO, E. (Orgs.). Telejornalismo em Questão. 1. ed. Florianópolis: Insular, 2014. v. 1. 376 p.

VIZEU, A.; MELLO, E.; PORCELLO, F.; COUTINHO, I. (Orgs.). Telejornal e praça pública: 65 anos de telejornalismo. 1. ed. Florianópolis: Insular, 2015. v. 1. 383 p.

\section{Gustavo Teixeira de Faria Pereira}

Mestrando em Comunicação pela Universidade Federal de Juiz de Fora e bolsista Capes. Jornalista formado pela UFJF, com experiência na área de Divulgação Científica e ênfase no Telejornalismo, atuando principalmente nos seguintes temas: telejornalismo, televisão pública, cidadania, 
telejornalismo local, pluralismo, diversidade, narrativas audiovisuais, fluxos comunicacionais e questões envolvendo o quarto e quinto poder/estado. Dentre as principais obras publicadas estão o artigo intitulado "Los medios de comunicación entre la cuarta y quinta potencia/estado: análisis de la segunda ronda de las elecciones presidenciales de 2018 en Brasil”, publicado na Revista Sphera Pública, v. 1, p. 72-90, 2019 e o capítulo intitulado "Nossas telas são plurais? As narrativas dos telejornais sobre mulheres, presos e o espaço local" no livro "Estudos Contemporâneos em telejornalismo- Narrativas de jornalismo para telas”. 1ed. Florianópolis: Insular, 2018, v. 1, p. 87102. E-mail: gustavo_tfp@yahoo.com.br.

Recebido em: 20.05.2019 Aprovado em: 26.07.2019 